\title{
Properties of in situ Composites Based on Semiflexible Thermotropic Liquid Crystalline Copolyesteramide and Polyamide 66 Blends
}

\author{
Sie Chin TJONG, ${ }^{\dagger}$ Robert Kwok Yu LI, and Xiaolin XIE ${ }^{\dagger \dagger}$ \\ Department of Physics and Materials Science, \\ City University of Hong Kong, Tat Chee Avenue, Kowloon, Hong Kong
}

(Received December 6, 1999; Accepted July 28, 2000)

\begin{abstract}
Liquid crystalline polymer-polyamide 66 (LCP/PA 66) blends were compounded using a Brabender mixing followed by compression moulding. The LCP employed was a semi-flexible liquid crystalline copolyesteramide based on $30 \mathrm{~mol} \%$ of $p$-amino benzoic acid (ABA) and $70 \mathrm{~mol} \%$ of poly(ethylene terephthalate) (PET). The in situ composites were investigated in terms of thermal, dynamic mechanical, morphological and rheological properties. The differential scanning calorimetry (DSC) results showed that the inclusion of the semi-flexible LCP into LCP/PA 66 blends retards the crystallization rate of PA 66. Furthermore, the melting temperature, the crystallization temperature and the degree of crystallinity of PA 66 were reduced considerably due to LCP addition. On the basis of DSC and dynamic mechanical analyses (DMA), PA 66 and LCP components of the blends were miscible in the melting state, but is partially miscible in the solid state. Hot-stage optical microscopy examination reveals that the LCP microfibrils with random orientation are formed in the PA 66 matrix of compression moulded LCP/PA 66 blends. In addition, the LCP domains within the PA 66 matrix deformed microfibrils, and oriented along the flow direction under the application of shearing force. The formation of microfibrils resulted in an increase in the storage modulus. Finally, the viscosity-concentration curves of the LCP/PA 66 blends exhibited an apparent maximum at $2.5 \mathrm{wt} \%$ LCP content, thereafter, the viscosity fell dramatically with increasing LCP concentrations.
\end{abstract}

KEY WORDS Polyamide 66 / Semiflexible Copolyesteramide/Miscibility / Viscosity /

Polymer blending is a common and versatile approach to develop newer materials with unique or combination of desirable properties. Pure liquid crystalline polymers exhibit superior physical properties such as good thermal and mechanical properties, excellent dimensional stability and melting processability, stiff molecular backbones and high degree of orientation in the molten state. Blending of the conventional thermoplastic polymers with liquid crystalline polymers has attracted considerable attention. ${ }^{1-9}$ This is because liquid crystalline polymers can deform into fine and elongated fibrils within an isotropic matrix under appropriate processing conditions. These liquid crystalline polymer fibrils can reinforce the thermoplastic matrix, thereby producing the so-called in situ polymer composites. However, the development of in situ composites is restricted by two factors. First, the melting temperatures of thermotropic liquid crystalline polymers (LCPs) are generally higher than those of the commodity engineering resins. At high processing temperature conditions, these resins tend to become unstable, thereby causing serious problems during fiber spinning or injection molding. In this respect, LCPs with lower melting points are beneficial. ${ }^{10}$ Many efforts ${ }^{11-13}$ have been dedicated to design and to synthesize polymers with their solid state to liquid crystalline phase transition temperatures lie well below the decomposition temperatures of thermoplastics. This can be achieved by introducing either flexible links or aliphatic chain segments in the main chains of LCPs. Second, the immiscibility and poor interfacial adhesion between the LCP dispersed phase and the thermoplastic matrix generally result in the LCP/thermoplastic blends having low tensile strength and impact toughness. A number of attempts have been made by the polymer scientists to improve the miscibility and the interfacial adhesion between these two distinct phases. The method widely used by them involves the addition of a suitable compatibilizer. A compatibilizer is a copolymer consisting of two blocks that are similar to the polymer components in the blends, or a functionalized polymer which undergoes chemical and/or physical reaction with dissimilar components of the blends. ${ }^{3,7-9,14-20}$ For example, Baird and coworkers $^{3,14-16}$ as well as Tjong and Meng ${ }^{7-9}$ reported that maleic-anhydride-grafted polypropylene (MAP) is an effective compatibilizer to improve the mechanical properties of LCP/polypropylene (PP) and LCP/ polyamide 6 blends. Weiss and co-workers ${ }^{17,18}$ indicated that a metal salt containing slightly sulfonated polystyrene ionomers can be used to compatibilize the LCP/ polyamide blends. Recently, Holsti-miettinen et al. ${ }^{20}$ pointed out that an epoxy-functionalized polymer addition improves the impact strength of the LCP/PP blends significantly. Another approach to increase the interfacial adhesion involves the modification of LCP structures. Several workers ${ }^{21-26}$ reported that the introduction of a long flexible spacer in the main chain of LCP tend to enhances the adhesion between the LCP and polymer matrix.

Polyamides (PA) such as PA 66 and PA 6 are used extensively in the manufacture of automobile parts, engineering structures and textile fibers owing to their high mechanical strength, stiffness and good processability. However, they exhibit a low heat deflection temperature, low crack propagation resistance, and high mois-

\footnotetext{
${ }^{\dagger}$ To whom correspondence should be addressed.

${ }^{\dagger+}$ On leave from the Department of Chemistry, Huazhong University of Science and Technology, Wuhan, China.
} 
ture absorption, which limit their usage as structural parts for industrial applications. These shortcomings can be overcome by blending with LCPs. The morphology and mechanical properties of molecular composites and in situ composites based on the PA and LCPs have been investigated by various workers. ${ }^{7,26-34}$ The LCPs used by them include wholly aromatic polyamide (such as poly ( $p$-benzamide) (PBA), poly ( $p$-phenylene terephthalamide) (PPTA), and poly ( $p$-phenylene diamine terephthalamide) (PPD-T), copolyester (such as Vectra A 950) and copolyesteramide (such as Vectra B 950). Their results indicated that the LCP additions lead to an increase in both tensile strength and modulus of blends, but to a decrease in the elongation at break owing to poor interfacial adhesion. As mentioned above, the introduction of a long flexible spacer in the main chain of liquid crystalline copolyester is an effective route to enhance the adhesion between the LCP and polyamide 66 matrix. ${ }^{35}$ Such LCPs containing flexible segments were synthesized successfully by Jackson and Kuhfuss ${ }^{36}$ in the past decade. They prepared semi-flexible thermotropic liquid crystalline copolyesteramides based on $p$-amino benzoic acid (ABA) and poly(ethylene terephthalate) (PET). The ABA segment of this LCP can produce some hydrogen bonding. Little information is available on the in situ composites containing LCP based on $\mathrm{ABA} / \mathrm{PET}$. In the present work, we attempt to incorporate semi-flexible ABA/PET liquid crystalline polymer into aliphatic polyamide matrix. The presence of ABA and the PET chain segments in LCP allows the formation of some specific interactions between the LCP and polyamide. This means that ABA segment of LCP can interact with polyamide via hydrogen bonding. Moreover, the thermal, dynamic mechanical, morphological, and rheological properties of LCP/PA 66 blends are studied.

\section{EXPERIMENTAL}

\section{Materials}

The LCP used in this work consisted of $30 \mathrm{~mol} \%$ of ABA and $70 \mathrm{~mol} \%$ of PET, and was designated as ABA 30/PET in this paper. Its synthesis procedures had been reported. ${ }^{36-38}$ Its intrinsic viscosity was $0.57 \mathrm{dL} \mathrm{g}^{-1}$. The glass transition and melting temperatures were 100 and $256^{\circ} \mathrm{C}$, respectively. PA 66 pellets (Novamid) supplied by Mitsubishi Engineering-Plastics Corp. (Taiwan) were used as the matrix material. The LCP and PA 66 pellets were dried in an oven at $120^{\circ} \mathrm{C}$ for $48 \mathrm{~h}$ before mixing.

\section{Sample Preparation}

LCP/PA 66 blends containing 2.5, 5, 10, 15, 25, and 35 wt\% LCP were prepared. The blending was performed in a Brabender Plasticorder equipped with a mixing chamber at $270^{\circ} \mathrm{C}$ and $50 \mathrm{rpm}$ for $5 \mathrm{~min}$. The resulting blends were then compression moulded into plates under a pressure of $10 \mathrm{MPa}$ at $270^{\circ} \mathrm{C}$. The moulded plates were finally cut into small pellets for the rheological analyses and other measurements.

\section{Differential Scanning Calorimetry (DSC)}

DSC measurements were conducted in a Perkin-
Elmer DSC-7 instrument at a heating rate of $10^{\circ} \mathrm{C} \mathrm{min}-1$ under dry nitrogen atmosphere. Prior to the DSC recording, all samples were heated to $280^{\circ} \mathrm{C}$, and kept at this temperature for $3 \mathrm{~min}$ to eliminate the influence of their previous thermal histories. They were then quenched to an ambient temperature. For non-isothermal crystallization measurement, the samples were heated to and kept at $280^{\circ} \mathrm{C}$ for $3 \mathrm{~min}$, and then cooled at a cooling rate of $10^{\circ} \mathrm{C} \min ^{-1}$.

\section{Dynamic Mechanical Analysis}

Dynamic mechanical analysis (DMA) of compression molded specimens was conducted with a DuPont dynamic mechanical analyser (model 983) at a fixed frequency of $1 \mathrm{~Hz}$ and an oscillation amplitude of $0.15 \mathrm{~mm}$. The temperature range studied was from -10 to $170^{\circ} \mathrm{C}$ with a heating rate of $2^{\circ} \mathrm{C} \mathrm{min}-1$.

\section{Optical Microscopy}

Polarizing optical microscopic examination was performed by using an Olympus BH 2-UMA polarizing microscope equipped with a hot stage and a temperature controller.

\section{Rheological Measurements}

Rheological properties of pure polymers and blends were measured using a capillary rheometer (model Goettfert Rheo 2003) at $270^{\circ} \mathrm{C}$. The capillary die used had a length (L) to diameter (D) ratio, i.e., $\mathrm{L} / \mathrm{D}$, of $30 / 1$ and an entrance angle of $180^{\circ}$. The Rabinowitch correction and Bagley correction were applied to all experimental data. The extrudates from the rheometer were quenched into a cold water bath in order to preserve the microstructure developed during the flow.

\section{Morphology Observations}

The morphologies of the fracture surfaces of all melt blends were observed in a scanning electron microscope (SEM, model JEOL JSM 820). The specimens used for SEM observations were taken from the strands extruded from the rheometer. These specimens were fractured in liquid nitrogen, and their fracture surfaces were coated with a thin layer of gold prior to SEM examinations.

\section{RESULTS AND DISCUSSION}

\section{Thermal Properties}

Figure 1 shows that DSC heating thermograms for PA 66 and LCP/PA 66 blends. PA 66 is known as a highly crystalline polymer that can crystallize rapidly, even under a quenched condition. And PA 66 exhibits two crystalline structures, i.e., $\alpha$ and $\gamma$ forms, which can undergo a reversible transformation at a low level of applied stress. ${ }^{39}$ From Figure 1, the appearance of two melting endotherms can be interpreted reasonably as the result of the sequential melting of the two different crystalline structures. Huang and Chang also reported a similar result for the PA 66 and PA 66/poly(butylene terephthalate) blends. ${ }^{40}$ From the DSC curves as shown in Figure 1 , the melting temperature $\left(T_{\mathrm{m}}\right)$ and heat of fusion $\left(\Delta H_{\mathrm{m}}\right)$ of these samples are determined. The heat of fusion is taken from the area of two melting peaks. The results are listed in Table I. Apparently, $T_{\mathrm{m}}$ of LCP in LCP/PA 




Figure 1. DSC heating scanning curves of PA 66 and blends. 0: LCP; 1: PA 66; 2. LCP(2.5)/ PA 66(97.5); 3. LCP(5)/ PA 66(95); 4. LCP(10)/ PA 66(90); 5. LCP(15)/ PA 66(85); 6. LCP(25)/ PA 66(75); 7. LCP(35)/ PA 66(65).

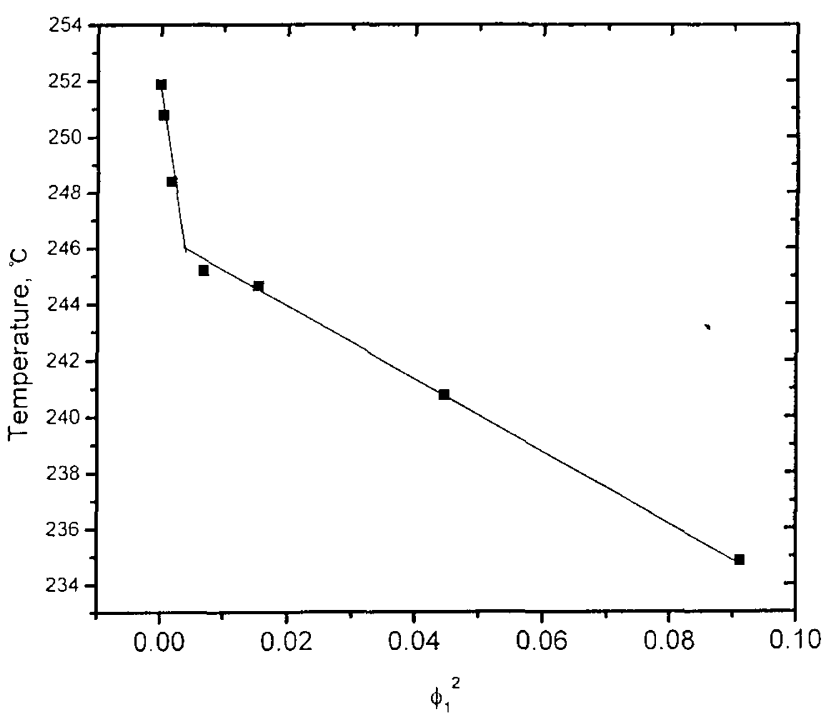

Figure 2. Variation of $T_{\mathrm{m}}$ of PA 66 phase in LCP/PA 66 blends with the square of volume fraction of LCP.

Table I. The thermal properties of LCP/PA 66 blends

\begin{tabular}{|c|c|c|c|c|c|c|c|}
\hline LCP/PA 66 & $\begin{array}{l}T_{\mathrm{m}} /{ }^{\circ} \mathrm{C} \\
\text { (onset) }\end{array}$ & $\begin{array}{l}T_{\mathrm{m}} /{ }^{\circ} \mathrm{C} \\
\text { (peak) }\end{array}$ & $\begin{array}{c}\Delta H_{\mathrm{m}} / \\
\mathrm{Jg}^{-1}\end{array}$ & $\begin{array}{l}T_{\mathrm{c}}{ }^{\circ} \mathrm{C} \\
\text { (onset) }\end{array}$ & $\begin{array}{l}\Delta H_{\mathrm{c}} / \\
\mathrm{Jg}^{-1}\end{array}$ & $\Delta T / /^{\circ} \mathrm{C}$ & $X_{\mathrm{c}} 1 \%$ \\
\hline $0 / 100$ & 251.9 & 260.2 & 66.4 & 233.2 & 62.8 & 27.0 & 34.1 \\
\hline $2.5 / 97.5$ & 250.8 & 259.5 & 58.5 & 230.0 & 57.5 & 29.5 & 30.0 \\
\hline $5 / 95$ & 248.4 & 257.1 & 58.0 & 228.4 & 58.4 & 28.7 & 29.8 \\
\hline $10 / 90$ & 245.2 & 255.7 & 60.7 & 224.6 & 59.3 & 31.1 & 31.2 \\
\hline $15 / 85$ & 244.7 & 254.7 & 50.0 & 224.8 & 56.1 & 29.9 & 25.7 \\
\hline $25 / 75$ & 240.8 & 251.3 & 43.7 & 219.3 & 52.2 & 32.0 & 22.4 \\
\hline $35 / 65$ & 234.9 & 244.6 & 38.9 & 210.8 & 45.3 & 33.8 & 20.0 \\
\hline $100 / 0$ & 256.0 & 261.5 & 3.4 & - & - & - & - \\
\hline
\end{tabular}

66 blends tends to decrease with increasing LCP concentrations. We can assume the LCP is a approximately a non-crystallizable component because its melting heat $\left(\Delta H_{\mathrm{m}}\right)$ is rather smaller than that of PA 66. From the Nishi-Wang theory, ${ }^{41}$ the following equation for the melting point depression of PA 66 in the blends can be determined from:

$$
\begin{aligned}
& T_{\mathrm{m}}=T_{\mathrm{m}}^{0}+T_{\mathrm{m}}^{0}\left(\frac{V_{2}}{\Delta H_{2}}\right) B \phi_{1}^{2} \\
& T_{\mathrm{m}}=T_{\mathrm{m}}^{0}+T_{\mathrm{m}}^{0}\left(\frac{V_{2}}{\Delta H_{2}}\right) B\left(1-\phi_{2}\right)^{2}
\end{aligned}
$$

Where $\phi_{1}$ and $\phi_{2}$ are the volume fractions of LCP and PA 66, respectively; and $\phi_{1}+\phi_{2}=1$. Moreover, $B$ is the polymer-polymer interaction energy density, and $B=$ $\chi_{12} R T / V_{1} ; T_{\mathrm{m}}^{0}$ and $T_{\mathrm{m}}$ are the melting temperatures of pure PA 66 and PA 66 in blends respectively; $\Delta H_{2} / V_{2}$ is the heat of fusion of $100 \%$ crystalline PA 66 per unit volume; $V_{1}$ is the molar volume of LCP; $\chi_{12}$ is the FloryHuggins interaction parameter. Accordingly, $\phi_{1}$ should be the volume fraction of LCP in the blending system. Equation 1 also reveals that the melting point depression is dependent on $B$ or $\chi_{12}$.
Table II. Values of the interaction energy density (B) and the interaction parameter $\left(\chi_{12}\right)$ for LCP/PA 66 blends at $270^{\circ} \mathrm{C}$

\begin{tabular}{ccc}
\hline LCP concentration & $\mathrm{B} / \mathrm{J} \mathrm{cm}^{-3}$ & \multicolumn{1}{c}{$\chi_{12}$} \\
\hline$<10 \mathrm{wt} \%$ & -7.65 & -0.21 \\
$>10 \mathrm{wt} \%$ & -0.49 & -0.014 \\
\hline
\end{tabular}

According to the group additive estimation, ${ }^{42}$ the densities of PA 66 and the LCP are estimated to be 1.085 and $1.35 \mathrm{~g} \mathrm{~cm}^{-3}$, respectively. From these data, we can convert the weight fractions into the volume fractions. The variations of the onset melting points of PA 66 with the square of the volume fraction of LCP is shown in Figure 2. The plots yield two straight lines with different slopes. The values of $B$ and $\chi_{12}$ determined at $270^{\circ} \mathrm{C}$ accordingly are reported in Table II. Apparently, $B$ and $\chi_{12}$ are determined to be $-7.65 \mathrm{~J} \mathrm{~cm}^{-3}$ and -0.21 , respectively for the blends containing LCP content $<10 \mathrm{wt}$ $\%$. However, $B$ and $\chi_{12}$ values become to $-0.49 \mathrm{~J} \mathrm{~cm}^{-3}$ and -0.014 accordingly when the LCP content reaches $10 \mathrm{wt} \%$ and above. It is well accepted that the miscibility of polymer components depends on the $B$ and $\chi_{12}$ values, i.e., the more negative $\chi_{12}$ value is, the more miscible the blend components are. As $B$ and $\chi_{12}$ show negative values in this study, thus the LCP appears to be miscible with PA 66 in the melting state. Such an improvement 


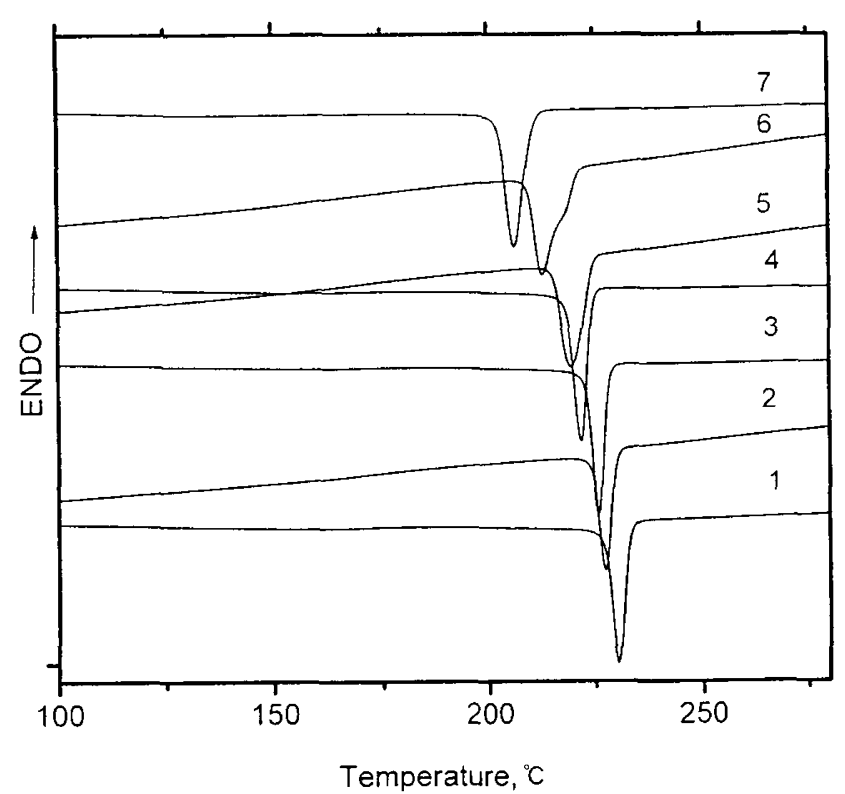

Figure 3. DSC cooling curves of PA 66 and LCP/PA 66 blends. 1: PA 66; 2. LCP(2.5)/ PA 66(97.5); 3. LCP(5)/ PA 66(95); 4. LCP(10)/ PA 66(90); 5. LCP(15)/ PA 66(85); 6. LCP(25)/ PA 66(75); 7. LCP (35) / PA 66(65).

in the miscibility of the blends with LCP content $<10 \mathrm{wt}$ $\%$ is suggested to be arisen from the amide and PET flexible chain segments of the LCP interact with PA 66 chains via hydrogen bond and physical entanglements, respectively. It is generally known that the chemical structure of the aliphatic polyamide molecules consists of amide groups separated by methylene sequences. The $\mathrm{NH}$ group tends to form strong hydrogen bonds with the $\mathrm{CO}$ group is the determining factor for the crystal structures found in nylons. In the case of LCP/PA blends, it is considered that the $\mathrm{NH}$ group of polyamide interacts with LCP via hydrogen bonds. ${ }^{7,8}$ As the LCP content is increased above $10 \mathrm{wt} \%$, the number of LCP domains increases, thereby forming interlocked domains which link themselves via hydrogen bonding. Thus less interactions occur between LCP domains and PA 66 matrix, i.e., the intermolecular bonding to link between LCP molecules themselves prevails over the LCP-PA 66 interaction. In this respect, the miscibility between the LCP and PA 66 become poorer compared with those of the blends with lower CP concentration.

According to the literature ${ }^{43}$ transamidation or transesterification reaction can lead to a depression of the melting temperature of blending component. However, the transamidation as well as transesterification reaction is unlikely to occur during mixing of the aromatic polymer with aliphatic polyamide or polyester for a relative short period of time. ${ }^{43-45}$ For example, transesterification reaction does not occur during blending of $\mathrm{PHB} /$ PET liquid crystalline copolyester with polycarbonate at $280^{\circ} \mathrm{C}$ for $45 \mathrm{~min} .^{46}$ Similarly, there exists no esteramide exchange reaction for PET/PA 66 blends mixed at $265^{\circ} \mathrm{C}$ for 25 min or extruded at $290-330^{\circ} \mathrm{C} .{ }^{47,48}$ As mentioned above, the mixing time for the LCP/PA 66 blends at $270^{\circ} \mathrm{C}$ is $5 \mathrm{~min}$, thus the possibility for the occurrence of transamidation reaction is rather small.

Figure 3 shows the DSC cooling thermograms for PA 66 and LCP/PA 66 blends. Apparently, the crystalliza-

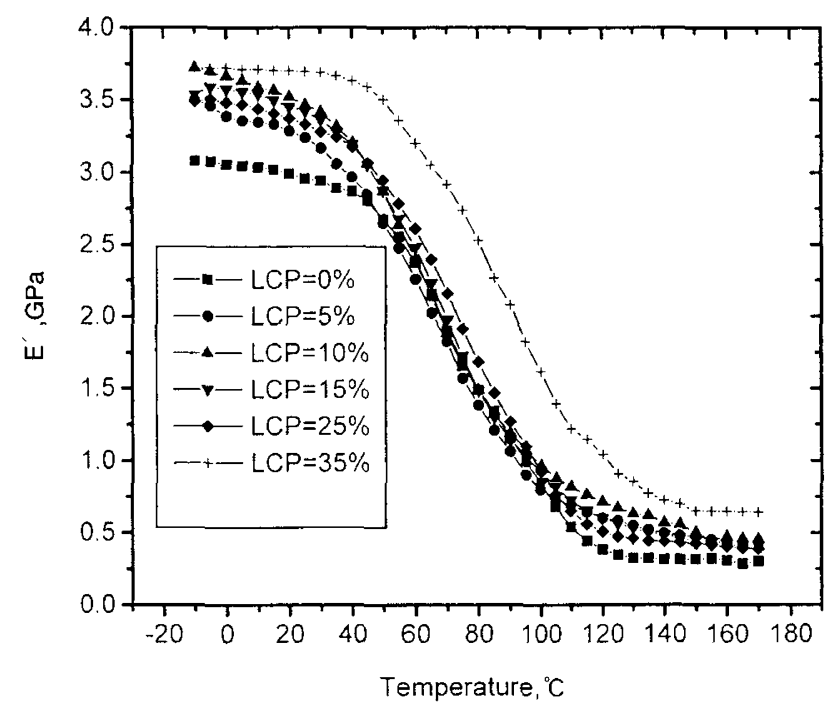

Figure 4. Variation of the storage modulus with temperature for PA 66 and LCP/PA 66 blends.

tion temperature $\left(T_{\mathrm{c}}\right)$ tends to shift to lower temperature region with increasing $\mathrm{LCP}$ content in the blends. The heat of crystallization $\left(\Delta H_{\mathrm{c}}\right)$ is determined from these DSC traces. The results are listed in Table I. From this table, $\Delta H_{\mathrm{c}}$ of PA 66 in LCP/PA 66 blends remains nearly unchanged with LCP content up to $10 \%$, thereafter it decreases with increasing LCP content. It implies that the LCP incorporation retards the crystallization of PA 66.

It is generally known that the degree of supercooling, $\Delta T$, can be used to characterize the crystallization behavior of polymer melts. It is defined by the difference between the peak melting temperature and onset crystallization temperature. An increase in $\Delta T$ generally indicates that the crystallization rate of polymer is retarded. The $\Delta T$ values of the specimens investigated are given in Table I. From this table, it is evident that the crystallization rate of the PA 66 phase is depressed in the LCP/PA 66 blends due to the introduction of LCP. Such a behavior has been observed in other polymer blends when the compatibility between their blend components is improved. ${ }^{49-52}$

The degree of crystallinity $\left(X_{c}\right)$ of LCP/PA 66 blends can be determined from their heat of fusion normalized to that of the PA 66 . The heat of fusion of $100 \%$ crystalline PA 66 is estimated to be $194.69 \mathrm{~J} \mathrm{~g}^{-1}$ according to the literature. ${ }^{42}$ The results are tabulated in Table I. It can be seen that $X_{\mathrm{c}}$ decreases significantly as the LCP content increases, thus the LCP addition affects the crystallinity of PA 66 dramatically. This observation is in accordance with the crystallinity behavior of compatibilized blends.

In general, the introduction of LCPs into LCP/thermoplastics blends is known to accelerate the crystallization rate and to enhance the degree of crystallinity of the thermoplastics. This is because the LCP dispersed phase acts as the sites for the nucleation of spherules. It is noted that the LCP used by these workers is Vectra A 950 copolyester, which is incompatible with the polymer matrix. ${ }^{53}$ From the DSC results, we can conclude that there exists some intermolecular interactions between the LCP and PA 66 phases, and these interactions tend 




Figure 5. Variation of the loss modulus with temperature for PA 66 and LCP/PA 66 blends.

Table III. The glass transition temperatures of LCP/PA 66 blends

\begin{tabular}{cccc}
\hline LCP/PA 66 & $T_{\mathrm{g} 1} /{ }^{\circ} \mathrm{C}$ & $T_{\mathrm{g} 2} /{ }^{\circ} \mathrm{C}$ & $T_{\mathrm{g} 2}-T_{\mathrm{g} 1} /{ }^{\circ} \mathrm{C}$ \\
\hline $0 / 100$ & 71.4 & - & - \\
$5 / 95$ & 72.7 & 117.2 & 44.5 \\
$10 / 90$ & 73.5 & 115.0 & 41.5 \\
$15 / 85$ & 75.2 & 112.2 & 37.0 \\
$25 / 75$ & 76.2 & 108.8 & 32.6 \\
$35 / 65$ & 79.5 & 105.2 & 25.7 \\
\hline
\end{tabular}

to improve the miscibility and the interfacial adhesion between them.

\section{Dynamic Mechanical Properties}

Figure 4 shows the variation of the storage modulus with temperature for PA 66 and LCP/PA 66 blends. The storage modulus of pure PA 66 over the whole temperature range studied is considerably lower than that of the LCP/PA 66 blends. Moreover, the storage modulus of the blends appears to increase with increasing LCP concentrations. Figure 5 shows the loss modulus vs. temperature for these specimens. The glass transition temperatures of PA 66 and the blends determined from the loss modulus are listed in Table III. The $T_{\mathrm{g}}$ for PA 66 is located at about $71^{\circ} \mathrm{C}$, and it is higher than the value $(\sim 66$ ${ }^{\circ} \mathrm{C}$ ) reported by Roerdink. ${ }^{54}$ This possibly results from the differences in annealing treatment and moisture content of PA $66 .^{39}$

As discussed above, the LCP is miscible with PA 66 in the melting state. However from Figure 5, the LCP/PA 66 blends show two glass transitions. It means that the blends are heterogeneous, i.e., consist of PA 66 and LCP phases. However, the two peaks shift toward each other with increasing LCP concentration. Thus the miscibility between the LCP and PA 66 phases is improved accordingly. These results indicate that PA 66 and LCP are partial miscible. In general, crystalline polymers form highly ordered stacks of crystalline lamellae which are separated by narrow amorphous interlayers in the solid state. Thus crystallization of polymers leads to a phase (a)

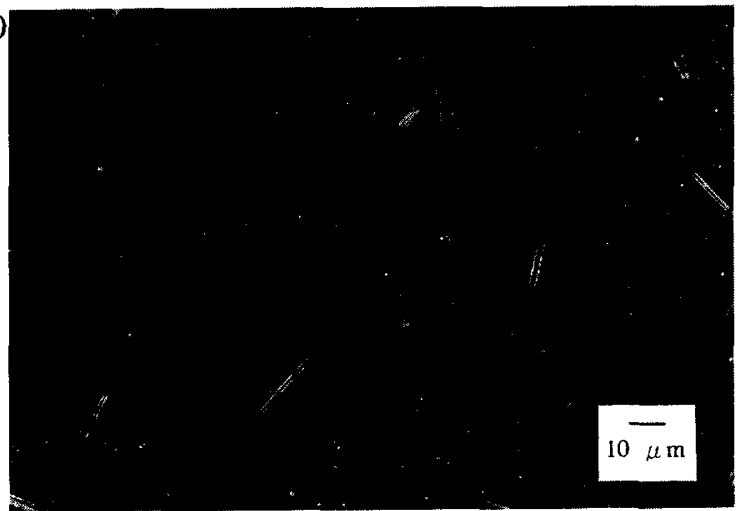

(b)

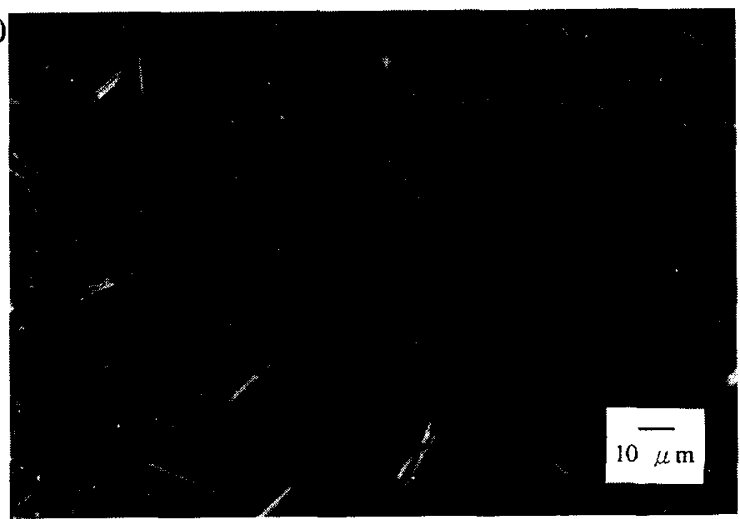

(c)

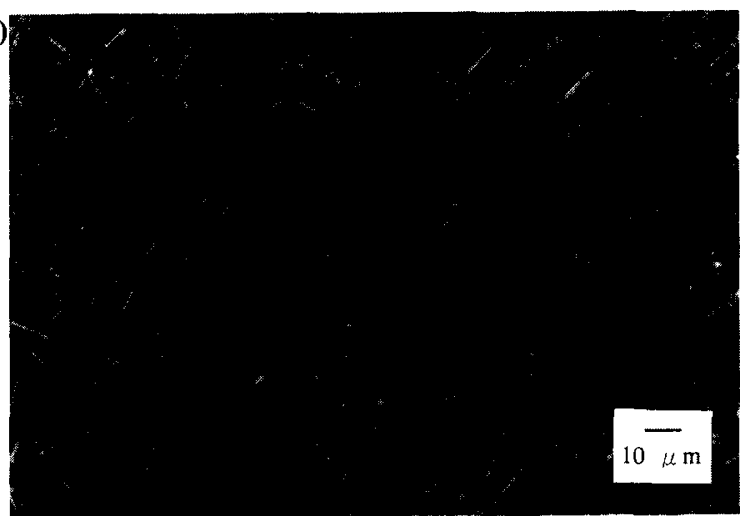

Figure 6. Polarized optical micrographs of the specimens investigated taken at $270^{\circ} \mathrm{C}$. (a) LCP(5)/ PA 66(95); (b) LCP(10)/ PA 66 (90); (c) LCP(35)/ PA 66(65).

separation. Such a behavior is also observed in poly(ethylene oxide) (PEO)/isotactic poly(methyl methacrylate) blend system. ${ }^{55,56}$

\section{Morphology}

Figures $6 a-6 c$ show the hot-stage polarized optical micrographs of compression moulded LCP/PA 66 blends. Some microfibres with random orientation are observed in the PA 66 matrix. The number of microfibres increases with increasing LCP content in the LCP/PA 66 blends. The LCP microfibrils in the PA 66 matrix contributes to an improvement in the mechanical stiffness of the LCP/PA 66 blends. This leads to the storage modulus of the blends tends to increase with increasing LCP concentrations as discussed above (Figure 4). It is interesting to note that these microfibrils transform into liquid crystalline domains within the PA 66 melts at a higher temperature (Figure 7a). When a shearing force is applied to the specimen, the LCP melt tends to orient 
(a)



(b)

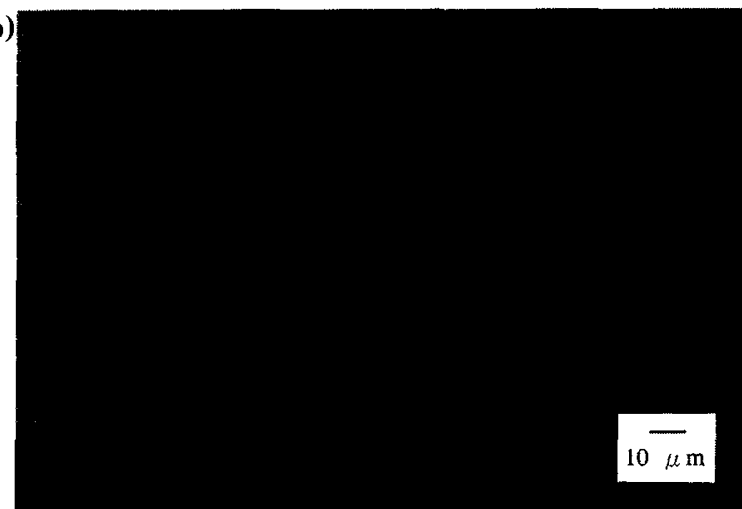

Figure 7. Polarized optical micrographs of LCP(10)/ PA 66(90) blend taken at $290^{\circ} \mathrm{C}$, (a) without and (b) with the application of a shearing force.

along the shearing direction (Figure 7b). As mentioned above, DSC results indicate that the LCP is miscible with PA 66 in the melt state. However, LCP phase of LCP/PA 66 blends at $290^{\circ} \mathrm{C}$ exhibits anisotropic domains within the isotropic PA 66 melt (Figure 7a). In other words, the LCP exhibit oriented microscopic domains at $290^{\circ} \mathrm{C}$ which is over the melting temperature $\left(T_{\mathrm{m}}\right)$ of LCP. It should be noted that $T_{\mathrm{m}}\left(265^{\circ} \mathrm{C}\right)$ of LCP in this study, and temperature used for polarized microscopic examination $\left(290^{\circ} \mathrm{C}\right)$ are much lower than the nematicisotropic transition temparature $\left(T_{\mathrm{NI}}\right)$ of the LCP. Therefore, the LCP microscopic domains in the LCP/PA 66 blends can be observed in the polarized microscope at $290^{\circ} \mathrm{C}$ (Figures $7 \mathrm{a}-7 \mathrm{~b}$ ). Figures $8 \mathrm{a}-8 \mathrm{~d}$ are the SEM micrographs showing the fracture surfaces of the LCP/ PA 66 blends. In these figures, the microfibrils formed in the PA 66 matrix are derived from LCP on the basis of optical microscopic examination as discussed above. The number of the microfibrils increases with increasing LCP content as expected. The LCP microfibrils remain intact with the matrix. And the LCP/PA 66 interface shows a rougher appearance morphology.

\section{Rheological Properties}

Figure 9 shows the rheological behavior of LCP, PA 66 and their blends taken at $270^{\circ} \mathrm{C}$. It can be seen that the LCP, PA 66 and their blends exhibit non-Newtonian and shear thinning behavior over a large range of shear rates. The LCP melt shows an unique rheological characteristic of the liquid crystalline polymers. Its apparent viscosity decreases greatly with shear rate up to $600 \mathrm{~s}^{-1}$, thereafter it approaches a steady state condition. So the (a)
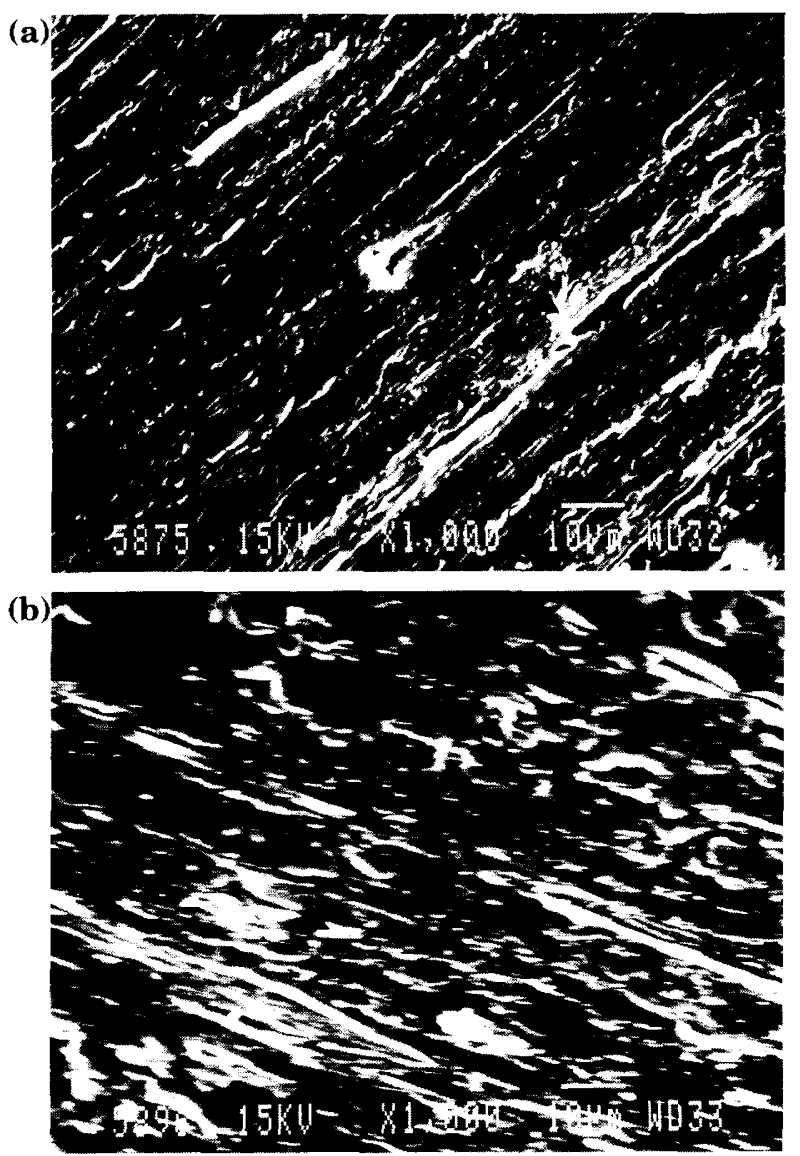

(c)

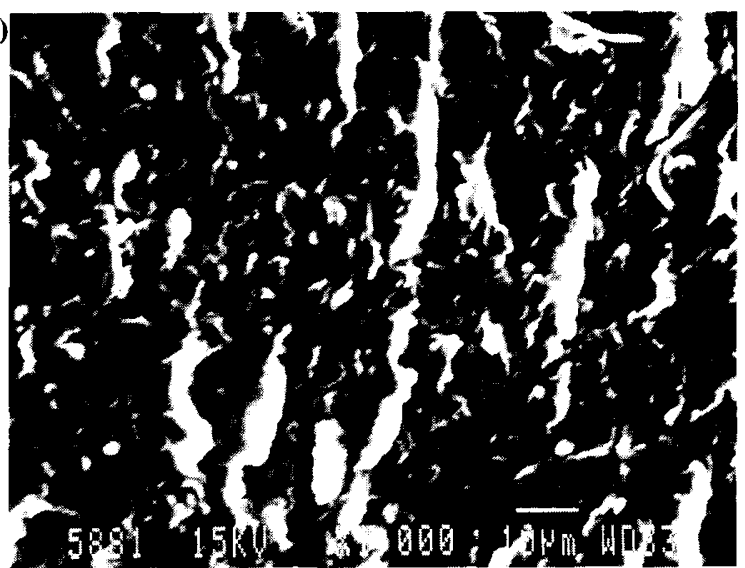

(d)

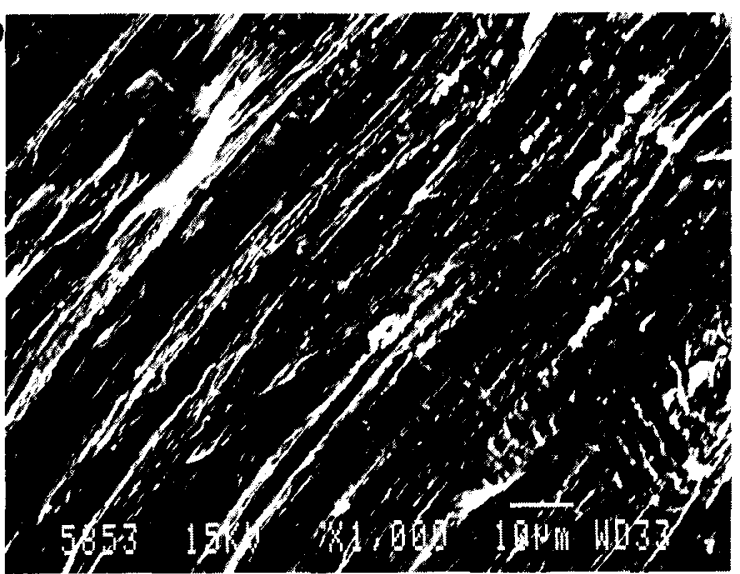

Figure 8. SEM micrographs of LCP/PA 66 blends. (a) LCP(2.5)/ PA 66(97.5); (b) LCP(5)/ PA 66(95); (c) LCP(10)/ PA 66(90); (d) LCP (25)/PA 66(75). 


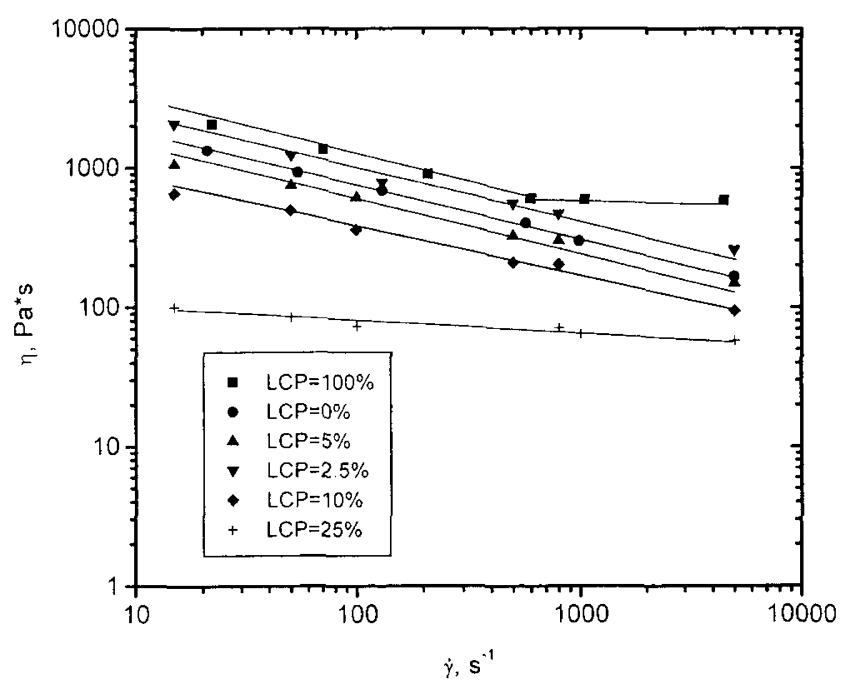

Figure 9. Rheological curves of LCP, PA 66 and their blends.

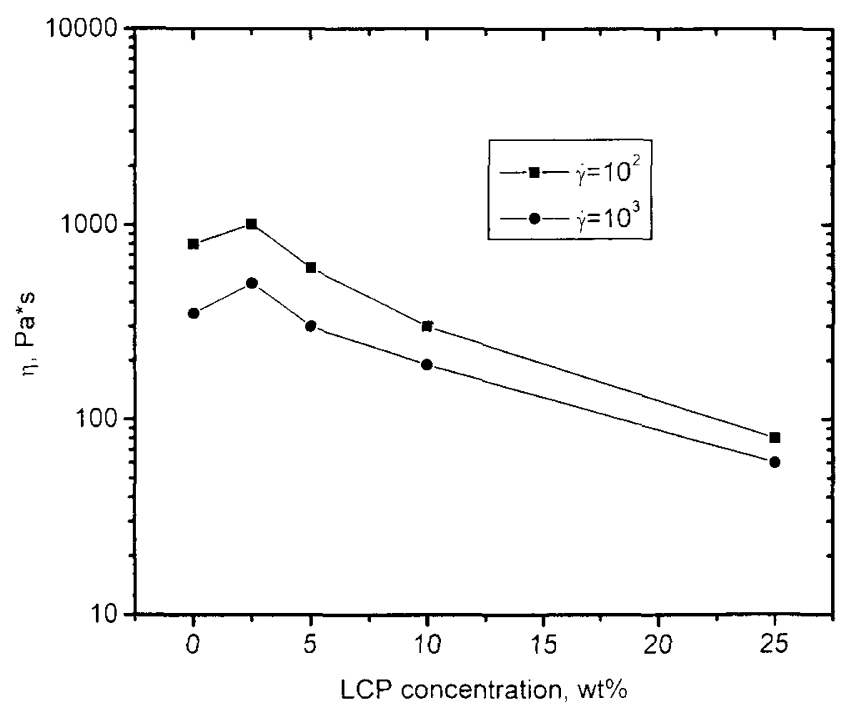

Figure 10. Apparent viscosity vs. LCP concentration curves for LCP/PA 66 blends.

viscosity curve of the LCP consists of two straight lines with different slopes, i.e., shear-thinning at lower shear rate regime and "pseudo-Newtonian plateau" at high shear rate region. The apparent viscosities of the LCP/ PA 66 blends containing LCP content $\geq 5 \%$ are lower than those of PA 66 and the LCP. Figure 10 shows the variation of apparent viscosity with the LCP concentration. This figure reveals that an apparent maximum occurs at about $2.5 \%$ LCP. At higher concentrations of LCP, the viscosity of the blends decreases dramatically. This behavior is similar to that of other LCP/PA 6 blends whose LCP constituents contain polyesteramide segments, i.e., Vectra B 950. La Mantia et al. ${ }^{33,34}$ observed an apparent maximum (1\% LCP) in the viscosityconcentration plots for Vectra B 950/PA 6. They attributed the viscosity maximum to the fibril formation and interfacial slip. As discussed above, many small LCP domains are formed in the blends containing low LCP content, thus hydrogen bonding is developed between the ABA segment of LCP and the PA 66 molecules. More- over, the PET chain moieties in the LCP can form interlock or physical entanglements with the PA 66 flexible chains. In this respect, the usual chain slip between the LCP and the matrix is replaced by these specific interactions, leading to an increase in melt viscosity. As the LCP content is increased to above $5 \%$, the number of LCP domains increases, and they act as a processing aid for the PA 66 matrix.

\section{CONCLUSIONS}

Semi-flexible ABA 30/PET LCP is synthesized and is incorporated into PA 66 polymer matrix. DSC results show that the introduction of the semi-flexible LCP into LCP/PA 66 blends retards the crystallization rate of PA 66. Moreover, the melting temperature, the crystallization temperature and the degree of crystallinity of PA 66 are reduced considerably due to LCP addition. PA 66 and LCP components in the blend are miscible in the melting state, but is partially miscible in the solid state on the basis of DSC and DMA analyses. Hot-stage optical microscopy examination reveals that the LCP microfibrils with random orientation are formed in the PA 66 matrix of compression moulded LCP/PA 66 blends. Under the application of shearing force, the LCP domains in the PA 66 matrix can deform into microfibrils, and orient themselves along the flow direction. The formation of microfibrils results in an increase in the storage modulus. Finally, the viscosity-concentration curves of the LCP/PA 66 blends shows an apparent maximum at $2.5 \mathrm{wt} \%$ LCP conctent, thereafter, it drops dramatically with increasing LCP concentrations.

Acknowledgment. This work was supported by a Strategic Grant (No. 7000607), City University of Hong Kong.

\section{REFERENCES}

1. G. Kiss, Polym. Eng. Sci., 27, 410 (1987).

2. T. Limtasiri and A. I. Isayev, J. Appl. Polym. Sci., 42, 2923 (1991).

3. A. Dutta, D. G. Baid, and H. H. Chen, Polymer, 34, 759 (1993).

4. L. Carpaneto, G. Lesage, R. Pisino, and V. Trefiletti, Polymer, 40, 1781 (1999).

5. S. C. Tjong, S. L. Liu, and R. K. Y. Li, J. Mater. Sci., 31, 479 (1996).

6. S. C. Tjong and Y. Z. Meng, Polym. Int., 42, 209 (1997)

7. S. C. Tjong and Y. Z. Meng, Polymer, 38, 4609 (1997).

8. Y. Z. Meng and S. C. Tjong, Polymer, 39, 99 (1998).

9. Y. Z. Meng, S. C. Tjong, and A. S. Hay, Polymer, 39, 1845 (1998).

10. B. P. Griffin and M. K. Cox, Br. Polym. J., 12, 147 (1980).

11. S. Antoun, R. W. Lenz, and J. I. Jin, J. Polym. Sci., Polym. Chem. Ed., 19, 1901 (1981).

12. B. Y. Shin, S. H. Jang, I. J. Chung, and B. S. Kim, Polym. Eng. Sci., 32, 73 (1992)

13. L. Carpaneto, G. Coasta, E. Marsano, B. Valenti, and M. Guenza, Polym. Adv. Technol, 4, 367 (1992).

14. R. E. S. Bretas and D. G. Baird, Polymer, 33, 5233 (1992).

15. A. Dutta and D. G. Baird, Polymer, 36, 505 (1995).

16. H. T. O'Donnell and D. G. Baird, Polymer, 36, 3113 (1995).

17. M. J. Sullivan and R. A. Weiss, Polym. Eng. Sci., 32, 517 (1992).

18. D. Dutta, R. A. Weiss, and J. He, Polymer, 37, 429 (1996).

19. M. M. Miller, J. M. Cowie, J. G. Tait, D. L. Brydon, and R. R. 
G. Mather, Polym. Eng. Sci., 36, 3107 (1995).

20. R. M. Holsti-Miettinen, M. T. Heino, and J. V. Seppala, J. Appl. Polym. Sci., 57, 573 (1995).

21. B. Y. Shin and I. J. Chung, Polym. J., 21, 85 (1988).

22. B. Y. Shin and I. J. Chung, Polym. Eng. Sci., 30, 13 (1990).

23. B. Y. Shin, S. H. Jang, I. J. Chung, and B. S. Kim, Polym. Eng. Sci., 32, 73 (1992)

24. S. Joslin, W. Jackson, and R. Farris, J. Appl. Polym. Sci., 54, 439 (1994).

25. H. Zhang, X. Du, D. Liu, and Q. Zhou, Acta Polym. Sinica (1), 54 (1998).

26. L. Carpaneto, G. Lesage, R. Pisino, and V. Trefiletti, Polymer, 40, 1781 (1999).

27. M. Takayanagi, T. Ogata, M. Morikawa, and T. Kai, J. Macromol. Sci., Phys., B17(4), 591 (1980).

28. R. A. Weiss, W. Huh, and L. Nicolais, Polym. Eng. Sci., 27, 684 (1987).

29. K. G. Blizard and D. G. Baird, Polym. Eng. Sci., 27, 653 (1987).

30. D. Beery, S. Kenig, and A. Siegmann, Polym. Eng. Sci., 31, 451 (1991)

31. S. H. Jang and B. S. Kim, Polym. Eng. Sci., 34, 847 (1994).

32. S. Yongsok, J. Appl. Polym. Sci., 64, 359 (1997).

33. F. P. La Mantia, A. Valenza, M. Paci, and P. L. Magagnini, J. Appl. Polym. Sci., 38, 583 (1989).

34. F. P. La Mantia, A. Valenza, M. Paci, and P. L. Magagnini, Polym. Eng. Sci., 30, 7 (1990).

35. B. Y. Shin and I. J. Chung, Polym. Eng. Sci., 30, 22 (1990).

36. W. J. Jackson and H. F. Kuhfuss, J. Appl. Polym. Sci., 25, 1685 (1980).

37. X. L. Xie, C. Yang, X. Tang, R. Li, and D. Wu, J. Functional Polym., 10, 23 (1997).

38. X. L. Xie and D. Wu, Chem. J. Chinese Univ., 18, 981 (1997).

39. M. I. Kohan, "Nylon Platics Handbook", Carl Hanser Verlag,
New York, N.Y. 1995.

40. C. C. Huang and F. C. Chang, Polymer, 38, 2135 (1992),

41. O. Olabisi, L. M. Robeson, and M. T. Shaw, "Polymer-Polymer Miscibility", Academic Press, New York, N.Y., 1979.

42. D. W. Van Krevelen, "Properties of Polymer", 3rd revised ed, Elsevier Scientific Publishing Co., Amsterdam, 1997.

43. A. Noshay and J. E. McGrath, "Block Copolymer Overview and Critical Survey", Academic Press, New York, N.Y., 1977.

44. W. Sweeny and J. Zimmerman, Encycl. Polym. Sci. Technol., 10, 483 (1969).

45. L. F. Beste and R. C. Houtz, J. Polym. Sci., 8, 395 (1952).

46. M. Guo and H. G. Zachmann, Polym. Prepr, Am. Chem, Soc., Div. Polym. Chem., 37, 825 (1996).

47. L. Z. Pillon and L. A. Utracki, Polym. Eng. Sci., 24, 1300 (1984).

48. L. Z. Pillon and L. A. Utracki, Polym. Process Eng., 4, 375 (1986).

49. T. G. Gopakumar, S. Ponrathnam, A. Lele, C. R. Rajan, and A. Fradet, Polymer, 40, 357 (1999).

50. Y. P. Chiou, D. Y. Chang, and F. C. Chang, Polymer, 37, 5655 (1996).

51. T. O. Ahn, S. Lee, H. M. Jeong, and S. W. Lee, Polymer, 37, 3559 (1996).

52. T. O. Ahn, S. C. Hong, H. M. Jeong, and J. H. Kim, Polymer, 38, 214 (1997)

53. S. C. Tjong, S. X. Chen, and R. K. Y. Li, J. Appl. Polym. Sci., 64, 705 (1997).

54. E. Roerdink and J. M. Warnier, Polymer, 26, 1582 (1985).

55. C. Marco, J. G. Faton, M. A. Gomez, H. Tanaka, and A. E. Tonelli, Macromolecules, 23, 2183 (1990).

56. J. Balarian, "Structure development during preparation, crystallization and melting of polymer mixtures" in X-Ray Investigations of Polymer Structures, A. Wtochowicz Ed., Proc. SPIE 3095, 1997 